\title{
ВЛИЯНИЕ ПОЧВЕННОЙ НЕОДНОРОДНОСТИ И ВНЕСЕНИЯ УСРЕДНЕННОЙ НОРМЫ АЗОТНЫХ УДОБРЕНИЙ НА УРОЖАЙНОСТЬ ЯРОВОЙ ПШЕНИЦЫ
}

\author{
S. V. Sherstobitov, N. V. Abramov
}

\section{THE EFFECT OF SOIL HETEROGENEITY AND THE INTRODUCTION OF AN AVERAGE RATE OF NITROGEN FERTILIZERS ON THE YIELD OF SPRING WHEAT}

Шерстобитов Сергей Владимирович - канд. с.-х. наук, доц. каф. почвоведения и агрохимии Государственного аграрного университета Северного Зауралья, г. Тюмень.

E-mail: sv5888857@yandex.ru

Абрамов Николай Васильевич - д-р с.-х. наук, проф., зав. каф. почвоведения и агрохимии Государственного аграрного университета Северного Зауралья, г. Тюмень.

E-mail: vip.anv.55@mail.ru

Цель исследований - установить интервал вариабельности содержания $\mathrm{N}-\mathrm{NO}_{3}$ в слое почвы 0-40 см по элементарным участкам поля, его связь с формированием урожайности яровой пшеницы для перехода на дифрференцированное внесение аммиачной селитры в режиме off-line nри посеве с использованием систем спутниковой навигации. На варианте без внесения минеральных удобрений внутрипольные колебания содержания нитратного азота составили 7,9-23,3 \%. На полях с высоким потенциальным плодородием чернозема выщелоченного получена хорошая урожайность яровой пшеницы даже без внесения минеральных удобрений - 3,38-4,65 m/2а. При этом колебания ее по элементарным участкам достигали от 2,86 до 4,77 m/2а. Между содержанием N-NO $\mathrm{N}_{3}$ в слое почвы 0-40 cм перед посевом и урожайностью яровой пшеницы установлена средняя и высокая корреляционная связь $r=0,52-0,97$. Применение удобрений традиционным способом (средняя норма на поле) снижало вариабельность содержания нитратного азота до 4,3-10,4 \%, а урожайность яровой пшеницы на фоне минеральных удобрений достигала 3,69-4,98 m/2а с колебаниями по элементарным участкам от 3,50 до $5,59 \mathrm{~m} / 2 a$. Коррелящия урожайности и со-
Sherstobitov Sergey Vladimirovich - Cand. Agr. Sci., Assoc. Prof., Chair of Soil Science and Agrochemistry, Northern Trans-Urals State Agrarian University, Tyumen.

E-mail: sv5888857@yandex.ru

Abramov Nikolay Vasilyevich - Dr. Agr. Sci., Prof., Head Chair of Soil Science and Agrochemistry, Northern Trans-Urals State Agrarian University, Tyumen.

E-mail: vip.anv.55@mail.ru

держания нитратного азота имела среднюю связь $(r=0,49)$, а по годам корреляционная связь наблюдалась от слабой $(r=0,13)$ до высокой $(r=-0,91)$. Данные исследований свидетельствуют о целесообразности перехода на диффференцированное внесение азотных удобрений по элементарным участкам в режиме off-line c использованием систем спутниковой навигации даже на полях с высоким потенциальным плодородием.

Ключевые слова: яровая пшеница, точное земледелие, вариабельность, выравненность, нитратный азот, аммиачная селитра.

The purpose of the researches was to establish the interval of variability of the content of $\mathrm{N}-\mathrm{NO} 3$ in the layer of the soil of $0-40 \mathrm{~cm}$ on elementary sites of the field, its connection with the formation of productivity of spring wheat for the transition to differentiated introduction of ammonium nitrate in the off-line mode in the crops with using the systems of satellite navigation. On the option without introduction of mineral fertilizers internal field fluctuations of the content of nitrate nitrogen made $7.9-23.3 \%$. On the fields with high potential fertility of chernozem lixivious good productivity of spring wheat even without introduction of mineral fertilizers equal to 3.38-4.65 thectare was received. 
Thus fluctuations on elementary sites reached from 2.86 to 4.77 thectare. Between the content of $\mathrm{N}-\mathrm{NO}_{3}$ in the layer of the soil of $0-40 \mathrm{~cm}$ before seeding and spring wheat productivity average and high correlation connection of $r=0.52-0.97$ was established. Using fertilizers in traditional way (average norm in the field) reduced the variability of the content of nitrate nitrogen by 4.3-10.4\%, and the productivity of spring wheat against mineral fertilizers reached 3.69-4.98 t/hectare with fluctuations on elementary sites from 3.50 to 5.59 t/hectare. The correlation of productivity and the content of nitrate nitrogen had average connection $(r=0.49)$, and by the years the correlation was observed from weak $(r=0.13)$ to high $(r=-0.91)$. The data of the researches testify to the expediency of the transition to differentiated introduction of nitric fertilizers on elementary sites in off-line mode using the systems of satellite navigation even on the fields with high potential fertility.

Keywords: spring wheat, precision farming, variability, alignment, nitrate nitrogen, ammonium nitrate.

Введение. В условиях Тюменской области применяют передовые технологии в системе земледелия [12, 13], высевают районированные сорта с высокими показателями качества $[9,11$, 16]. Необходимо уделять внимание агрохимическому обследованию почв, текущей нитрификации, расчету доз удобрений на планируемую урожайность $[6-8,10]$.

Азот в почвах Тюменской области находится в минимуме среди макроэлементов, что связанно с малогумусностью почв и высокой его подвижностью в нитратной и газообразной форме. Он входит в состав белков, хлорофилла, ферментов, витаминов, оказывает влияние на формирование урожайности культур и качество продукции [5].

Известно три формы азота: амидная, аммонийная, нитратная, - последняя форма, как правило, достаточно хорошо характеризует ситуацию обеспеченности растений азотным питанием $[5,8]$. Почвам Западной Сибири характерен широкий диапазон пространственной изменчивости $\mathrm{N}^{-\mathrm{NO}_{3}}$ в агроландшафтах.

Традиционный подход в расчете потребности в минеральных удобрениях и внесение их с усредненной нормой по полю, как правило, не приводит к ожидаемым результатам. Нами предложена методика составления агрохимических картограмм и технология диффреренцированного внесения азотных удобрений по элементарным участкам поля при посеве в режиме off-line c применением (систем спутниковой навигации) БНК «Агронавигатор» в комплекте с линейным электроактуатором [1, 2, 17, 18, 20].

Диффреренцированное внесение минеральных удобрений успешно внедрено в хозяйствах Тюменской, Свердловской, Оренбургской областях и Краснодарском крае более чем на 300 тыс. га.

По мнению ученых В. В Якушева, В. Г. Сычева, Р. А. Афранасьева, Е. А. Семенова, применение средств химизации с использованием космических систем является перспективным направлением в точном земледелии и может реально управлять продукционными процессами в агроценозах $[3,4,14,15,19]$.

Однако у товаропроизводителей аграрного сектора встает вопрос, при каком уровне вариабельности почвенного плодородия целесообразно применение дифференцированного внесения минеральных удобрений. Особенный интерес проявляют хозяйствующие субъекты АПК, у которых в структуре почвенного покрова основная доля приходится на черноземы, серые лесные почвы - то есть почвы с высоким потенциальным плодородием.

Цель исследований: установить интервал вариабельности содержания $\mathrm{N}_{-} \mathrm{NO}_{3}$ в слое почвы 0-40 см по элементарным участкам поля, его связь с формированием урожайности яровой пшеницы для перехода на диффреренцированное внесение аммиачной селитры в режиме off-line при посеве с использованием систем спутниковой навигации.

Материалы и методы исследований. Научно-производственные опыты были заложены в АО ПЗ «Учхоз ГАУ Северного Зауралья». Почва опытных полей чернозем выщелоченный, в комбинации с темно-серыми лесными почвами и пятнами солодей. Содержание гумуса - от 6,0 до 8,0 \%, рН солевой вытяжки - 6,0-7,0 ед., подвижного фросфрора - от 110,0 до 160,0 мг/кг почвы, обменного калия - от 111,0 до 128,0 мг/кг почвы. Эти почвы, благодаря научно обоснованной системе земледелия, имеют высокий уровень агрохимических, водно-физических показателей плодородия. Нитратный азот определяли в ранневесенний период по ГОСТ 26951-86. Рассчитывали пестроту (коэффиициент вариации) 
для выявления степени выраженности неоднородности нитратного азота по элементарным участкам в варианте (V, \%), коэфффициент корреляции (r) для определения степени связей между урожайностью и содержанием нитратного азота, обработку данных вели в программных продуктаx Snedecor и Excel, интерпретация данных - по Б. А. Доспехову. Агротехника опыта описана нами в более ранних работах $[2,17,18]$.

Отбор почвенных образцов проводили в ранневесенний период в слое почвы 0-40 см тростью Осипова с географической привязкой к местности (ручной навигатор Garmin). На контроле не вносили минеральные удобрения, а при традиционном способе внесения рассчитывали методом элементарного баланса по каждому элементарному участку. Усредненную норму вносили по варианту при посеве яровой пшеницы.

Результаты исследований и их обсуждение. На контрольном варианте в 2017 г. содержание $\mathrm{N}-\mathrm{NO}_{3}$ в слое 0-40 см перед посевом яровой пшеницы было низким - 7,8 мг/кг почвы (по Кочергину, 1984). Коэфффициент пространственной вариации $\mathrm{N}_{-} \mathrm{NO}_{3}$ составил 7,9\%, что свидетельствует о незначительной пестроте признака.
Однако даже при низкой пространственной вариабельности нитратного азота в весенний период корреляционная связь его содержания с урожайностью яровой пшеницы была сильной $(r=0,97)$. Это подтверждают фактические данные содержания $\mathrm{N}^{-N_{3}} 3$ в почве и продуктивность яровой пшеницы (табл. 1, 2). Так, в 2017 г. при самых низких значениях нитратного азота в 7,1 мг/кг почвы на элементарном участке № 11 получена и самая низкая урожайность яровой пшеницы - 2,86 т/га.

При относительно самом высоком содержании $\mathrm{N}-\mathrm{NO}_{3}-8,3$ мг/кг почвы на элементарном участке № 10 получена самая высокая урожайность - 3,94 т/га.

Степень неоднородности содержания нитратного азота в 2018 г. была значительной, внутрипольная вариабельность $\mathrm{N}^{-\mathrm{NO}_{3}}$ перед посевом составила 23,3 \%. На элементарном участке № 5 при наибольшем содержании азота получена самая высокая урожайность яровой пшеницы - 3,74 т/га. На данном поле установлена средняя корреляционная связь $(r=0,64)$ между содержанием $\mathrm{N}_{-} \mathrm{NO}_{3}$ в слое почвы 0-40 см и урожайностью яровой пшеницы.

Таблица 1

\section{Содержание нитратного азота в слое почвы 0-40 см, мг/кг почвы, и его пространственное вариабельность, \%}

\begin{tabular}{|c|c|c|c|c|c|c|}
\hline \multirow[b]{2}{*}{ Вариант } & \multicolumn{2}{|c|}{2017 г. (поле № 63) } & \multicolumn{2}{|c|}{2018 г. (поле № 76) } & \multicolumn{2}{|c|}{2019 г. (поле № 65) } \\
\hline & $\begin{array}{c}\text { Номер } \\
\text { элементарного } \\
\text { участка }\end{array}$ & $\mathrm{N}-\mathrm{NO}_{3}$ & $\begin{array}{c}\text { Номер } \\
\text { Элементарного } \\
\text { участка }\end{array}$ & $\mathrm{N}-\mathrm{NO}_{3}$ & $\begin{array}{c}\text { Номер } \\
\text { Элементарного } \\
\text { участка }\end{array}$ & $\mathrm{N}-\mathrm{NO}_{3}$ \\
\hline \multirow{7}{*}{ B1 } & 7 & 7,9 & 7 & 4,0 & 3 & 11,2 \\
\hline & 10 & 8,3 & 5 & 6,0 & 18 & 9,8 \\
\hline & 11 & 7,1 & 14 & 4,2 & 7 & 11,8 \\
\hline & Среднее & 7,8 & Среднее & 4,7 & Среднее & 10,9 \\
\hline & $\operatorname{Max}$ & 8,3 & $\operatorname{Max}$ & 6,0 & $\operatorname{Max}$ & 11,8 \\
\hline & Min & 7,1 & Min & 4,0 & Min & 9,8 \\
\hline & Вариабельность, \% & 7,9 & Вариабельность, \% & 23,3 & Вариабельность, \% & 9,4 \\
\hline \multirow{7}{*}{ B2 } & 5 & 9,8 & 11 & 4,4 & 9 & 12,0 \\
\hline & 12 & 9,1 & 2 & 4,2 & 4 & 11,5 \\
\hline & 14 & 9,1 & 15 & 3,7 & 20 & 9,8 \\
\hline & Среднее & 9,3 & Среднее & 4,1 & Среднее & 11,1 \\
\hline & Max & 9,8 & Max & 4,4 & Max & 12,0 \\
\hline & Min & 9,1 & Min & 3,7 & Min & 9,8 \\
\hline & Вариабельность, \% & 4,3 & Вариабельность, \% & 8,8 & Вариабельность, \% & 10,4 \\
\hline
\end{tabular}

Примечание: В1 - контроль (без внесения удобрений); В2 - традиционный способ внесения (средняя доза аммиачной селитры по полю-варианту).

В условиях 2019 г. на поле № 65 без внесения минеральных удобрений внутрипольная рота признака незначительная, выравненность 
его значительная. При средней обеспеченности нитратным азотом 10,9 мг кг/почвы корреляция между урожайностью и содержанием $\mathrm{N}-\mathrm{NO}_{3}$ перед посевом яровой пшеницы была средняя $(r=-0,52)$. Минимальное содержание $\mathrm{N}^{-N_{3}}$
9,8 мг/мг почвы было установлено на участке № 18, максимальное - 11,8 мг/кг почвы на участке № 7. В среднем по варианту обеспеченность нитратным азотом низкая по Кочергину при содержании 11,8 мг/кг почвы.

Таблица 2

Урожайность яровой пшеницы, т/га, и ее пространственная вариабельность, \%

\begin{tabular}{|c|c|c|c|c|c|c|}
\hline \multirow[b]{2}{*}{ Вариант } & \multicolumn{2}{|c|}{2017 г. (поле № 63) } & \multicolumn{2}{|c|}{2018 г. (поле № 76) } & \multicolumn{2}{|c|}{2019 г. (поле № 65) } \\
\hline & 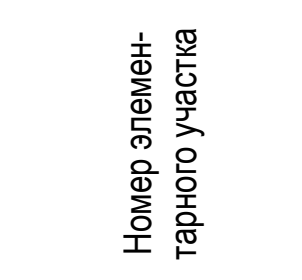 & 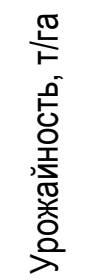 & 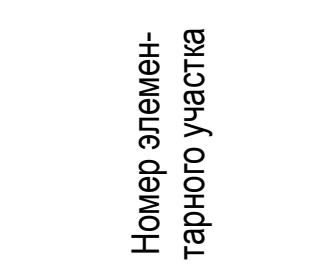 & 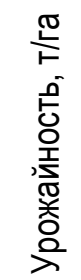 & 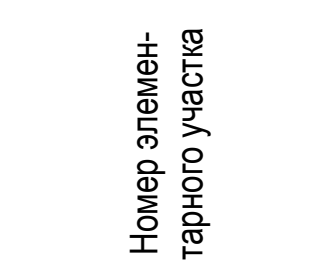 & 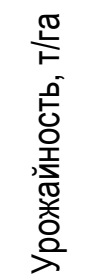 \\
\hline \multirow{8}{*}{ B1 } & 7 & 3,34 & 7 & 3,54 & 3 & 4,49 \\
\hline & 10 & 3,94 & 5 & 3,74 & 18 & 4,77 \\
\hline & 11 & 2,86 & 14 & 3,01 & 7 & 4,68 \\
\hline & Среднее & 3,38 & Среднее & 3,43 & Среднее & 4,65 \\
\hline & Max & 3,94 & Max & 3,74 & Max & 4,77 \\
\hline & Min & 2,86 & Min & 3,01 & Min & 4,49 \\
\hline & Вариабельность, \% & 16,0 & Вариабельность, \% & 11,0 & Вариабельность, \% & 3,1 \\
\hline & $r$ & 0,97 & $r$ & 0,64 & $r$ & $-0,52$ \\
\hline \multirow{8}{*}{ B2 } & 5 & 3,72 & 11 & 4,54 & 9 & 4,75 \\
\hline & 12 & 3,86 & 2 & 4,62 & 4 & 5,59 \\
\hline & 14 & 3,50 & 15 & 4,10 & 20 & 4,59 \\
\hline & Среднее & 3,69 & Среднее & 4,42 & Среднее & 4,98 \\
\hline & Max & 3,86 & Max & 4,62 & $\operatorname{Max}$ & 5,59 \\
\hline & Min & 3,5 & Min & 4,10 & Min & 4,59 \\
\hline & Вариабельность, \% & 4,9 & Вариабельность, \% & 6,3 & Вариабельность, \% & 10,8 \\
\hline & $r$ & 0,13 & $r$ & 0,91 & $r$ & 0,44 \\
\hline $\begin{array}{c}\text { Прибавка, } \\
\text { т/га }\end{array}$ & - & 0,31 & - & 0,99 & - & 0,33 \\
\hline
\end{tabular}

Таким образом, на полях с высоким потенциальным плодородием черноземов, темносерых лесных почв получены высокие урожаи яровой пшеницы без применения минеральных удобрений 2,86-4,65 т/га. При этом даже в интервале очень низкой и средней обеспеченности минеральным азотом зерновых (4,7-10,9 мг/кг почвы перед посевом) отмечено влияние его внутрипольной пестротой 7,9-23,3 \% на продуктивность яровой пшеницы с вариабельностью 3,1-16,0 \% по элементарным участкам. Данный фракт мы объясняем особенностью формирования азотного режима в условиях Тюменской области, активизацией биологических процессов в период вегетации растений. Это подтверждает средняя и высокая корреляционная связь $(r=0,52-0,97)$ между урожайностью яровой пшеницы и содержанием $\mathrm{N}_{-} \mathrm{NO}_{3}$ в слое почвы 0-40 cM.

Внесение аммиачной селитры на планируемую урожайность яровой пшеницы 3,5-4,0 т/га традиционным способом с учетом содержания нитратного азота в среднем по элементарным участкам поля: 109,0 кг/га в 2017 г.; 155 кг/га в 2018 г.; 117 кг/га в 2019 г., - позволило получить урожайность зерна яровой пшеницы 3,69; 4,42; 4,98 т/га соответственно. При этом азотные удобрения в опытах снижали уровень пространственной вариабельности содержания $\mathrm{N}-\mathrm{NO}_{3}$ в почвах до 4,3-10,4 \%, а урожайности яровой 
пшеницы - до 4,9-10,8 \% по элементарным участкам. Соответственно, внесение минеральных удобрений традиционным способом со средней нормой по полю способствовало формированию продуктивности яровой пшеницы по элементарным участкам с высокой выравненностью 89,2-95,1\%.

Однако даже в сложившейся ситуации корреляционная связь между содержанием нитратного азота в почве и урожайностью яровой пшеницы колебалась по годам исследований от слабой до сильной $r=0,13 ; 0,44 ; 0,91$.

Таким образом, применение азотных удобрений традиционным способом с усредненной нормой по полю снижает вариабельность внутрипольного содержания $\mathrm{N}^{-\mathrm{NO}_{3}}$ по элементарным участкам до 4,3-10,4 \% и урожайности яровой пшеницы - до 4,9-10,8 \%.

Средняя и высокая корреляционная связь между содержанием нитратного азота в слое 040 см и урожайностью дает основание использовать диффференцированное внесение азотных удобрений в режиме off-line даже на высокоплодородных почвах, начиная с внутрипольной вариабельности азота 8,0 \% и более.

\section{Выводы}

1. На полях с высоким потенциальным плодородием без применения минеральных удобрений, но в интервале очень низкой и средней обеспеченности нитратным азотом зерновых (4,7-10,9 мг/кг почвы) перед посевом отмечается влияние его внутрипольной пестроты 7,923,3\% на урожайность с ее вариабельностью 3,1-16,0 \% по элементарным участкам поля.

2. Применение азотных удобрений с усредненной нормой по полю снижает вариабельность внутрипольного содержания $\mathrm{N}-\mathrm{NO}_{3}$ по элементарным участкам до 4,3-10,4 \% и вариабельность урожайности яровой пшеницы по элементарным участкам до 4,8-10,8 \%.

3. Зависимость формирования продуктивности яровой пшеницы от внутрипольной вариабельности $\mathrm{N}-\mathrm{NO}_{3}$ подтверждается средней и высокой корреляционной связью $(r=0,52-0,97)$ между содержанием азота в весенний период и урожайностью яровой пшеницы.

4. Средняя и высокая корреляционная связь между содержанием нитратного азота и уро- жайностью яровой пшеницы дает основание для перехода на дифференцированное внесение азотных удобрений на высокоплодородных почвах, начиная с внутрипольной вариабельности азота, составляющей 8,0 \%.

\section{Литература}

1. Абрамов Н.B., Семизоров C.A. Геоинформационные системы для агротехнологий высокой интенсивности // Коняевские чтения: сб. науч. тр. VI Междунар. науч.-практ. конфр. Екатеринбург, 2018. С. 197-199.

2. Абрамов Н.В., Шерстобитов С.В. Диффреренцированное внесение удобрений с использованием спутниковой навигации // Агрохимия. 2018. № 9. С. 40-49.

3. Афранасьев Р.А., Беленков А.И. Внутрипольная вариабельность плодородия почв, состояния посевов и урожайности полевых культур в точном земледелии // Фермер. Поволжье. 2016. № 4 (46). С. 36-40.

4. Афранасьев Р.А., Иванчик В.А. Урожайность и качество зерна яровой пшеницы в условиях Нечерноземья при внесении минеральных удобрений // Плодородие. 2019. № 6 (111). С. 11-14.

5. Гамзиков Г.П. Агрохимия азота в агроценозах. Новосибирск, 2013. 790 с.

6. Демиденко Г.А. Агрохимический мониторинг сельскохозяйственных земель Красноярской лесостепи // Вестник КрасГАУ. 2017. № 7 (130). C. 3-9.

7. Дёмин Е.А., Ерёмин Д.И. Влияние минеральных удобрений на текущую нитрификацию чернозема выщелоченного под кукурузой в условиях лесостепной зоны Зауралья // Актуальные проблемы рационального использования земельных ресурсов: сб. ст. по мат-лам III Всерос. (национальной) науч.практ. конф. / под общ. ред. С.Ф. Сухановой. с. Лесниково, 2019. С. 26-31.

8. Ермохин Ю.И., Бобренко И.А. Оптимизация минерального питания сельскохозяйственных культур на основе «ПРОД». Омск, 2005. $284 \mathrm{c}$.

9. Казак А.А., Логинов Ю.П., Ерёмин Д.И. Влияние минеральных удобрений на урожайность и качество семян сортов пшеницы в северной лесостепи Тюменской об- 
ласти // Аграрная наука Евро-СевероВостока. 2019. Т. 20, № 3. С. 219-229.

10. Конончук В.В., Гончаренко М.С. К вопросу о расчете доз удобрений на планируемый урожай зерновых культур в Центральном Нечерноземье // Зерновое хозяйство России. 2012. № 4. С. 50-54.

11. Логинов Ю.П., Казак А.А. Урожайность и качество семян сортов пшеницы Тюменская юбилейная и Тюменочка в зависимости от сроков сева и норм высевав северной лесостепи Тюменской области // Вестник КрасГАУ. 2019. № 5 (146). С. 50-62.

12. Миллер С.С., Рзаева В.В. Урожайность яровой пшеницы по способам обработки почвы в зернопропашном севообороте северной лесостепи Тюменской области // АгроЭкоИнфо. 2018. № 4 (34). С. 13.

13. Рзаева В.В. Влияние агротехнических приемов на продуктивность культур севооборота // Известия Оренбургского государственного аграрного университета. 2019. № 4 (78). C. 18-20.

14. Семенова Е.А., Афранасьев Р.А. Агроэкономическая эффективность применения минеральных удобрений под яровую пшеницу в условиях Зауралья // Плодородие. 2019. № 2 (107). C. 11-13.

15. Сычев В.Г., Афранасьев Р.А. Робототехника в технологиях точного земледелия // Плодородие. 2016. № 3 (90). С. 2-6.

16. Тоболова Г.В., Летяго Ю.А., Белкина Р.И. Оценка сортов мягкой яровой пшеницы по технологическим свойствам и биохимическим признакам // Агропродовольственная политика России. 2015. № 5 (41). С. 64-67.

17. Чикишев Д.В., Абрамов Н.В., Ларина Н.С. Влияние азотных удобрений на аминокислотный состав зерна яровой пшеницы // Вестник Башкирского гос. аграр. ун-та. 2019. № 3 (51). C. 20-25.

18. Шерстобитов С.В. Дифференцированное внесение азотных удобрений с использованием систем спутниковой навигации: автореф. дис. ... канд. с.-х. наук / Всерос. науч.исслед. ин-т агрохимии им. Д.Н. Прянишникова. М., 2015. 22 с.

19. Якушев В.В. Точное земледелие: теория и практика. СПб., 2016. 364 с.

\section{Literatura}

1. Abramov N.V., Semizorov S.A. Geoinformacionnye sistemy dlja agrotehnologij vysokoj intensivnosti // Konjaevskie chtenija: sb. nauch. tr. VI Mezhdunar. nauch.-prakt. konf. Ekaterinburg, 2018. S. 197-199.

2. Abramov N.V., Sherstobitov S.V. Differencirovannoe vnesenie udobrenij s ispol'zovaniem sputnikovoj navigacii // Agrohimija. 2018. № 9. S. 40-49.

3. Afanas'ev R.A., Belenkov A.I. Vnutripol'naja variabel'nost' plodorodija pochv, sostojanija posevov i urozhajnosti polevyh kul'tur $v$ tochnom zemledelii // Fermer. Povolzh'e. 2016. № 4 (46). S. 36-40.

4. Afanas'ev R.A., Ivanchik V.A. Urozhajnost' i kachestvo zerna jarovoj pshenicy $v$ uslovijah Nechernozem'ja pri vnesenii mineral'nyh udobrenij // Plodorodie. 2019. № 6 (111). S. 11-14.

5. Gamzikov G.P. Agrohimija azota v agrocenozah. Novosibirsk, 2013. $790 \mathrm{~s}$.

6. Demidenko G.A. Agrohimicheskij monitoring sel'skohozjajstvennyh zemel' Krasnojarskoj lesostepi // Vestnik KrasGAU. 2017. № 7 (130). S. 3-9.

7. Djomin E.A., Erjomin D.I. Vlijanie mineral'nyh udobrenij na tekushhuju nitrifikaciju chernozema vyshhelochennogo pod kukuruzoj $\mathrm{v}$ uslovijah lesostepnoj zony Zaural'ja // Aktual'nye problemy racional'nogo ispol'zovanija zemel'nyh resursov: sb. st. po mat-lam III Vseros. (nacional'noj) nauch.-prakt. konf. I pod obshh. red. S.F. Suhanovoj. s. Lesnikovo, 2019. S. 26-31.

8. Ermohin Ju.I., Bobrenko I.A. Optimizacija mineral'nogo pitanija sel'skohozjajstvennyh kul'tur na osnove «PROD». Omsk, 2005. $284 \mathrm{~s}$.

9. Kazak A.A., Loginov Ju.P., Erjomin D.I. Vlijanie mineral'nyh udobrenij na urozhajnost' i kachestvo semjan sortov pshenicy $v$ severnoj lesostepi Tjumenskoj oblasti // Agrarnaja nauka Evro-Severo-Vostoka. 2019. T. 20, № 3. S. 219-229.

10. Kononchuk V.V., Goncharenko M.S. K voprosu o raschete doz udobrenij na planiruemyj urozhaj zernovyh kul'tur v Central'nom Nechernozem'e // Zernovoe hozjajstvo Rossii. 2012. № 4. S. 50-54. 
11. Loginov Ju.P., Kazak A.A. Urozhajnost' i kachestvo semjan sortov pshenicy Tjumenskaja jubilejnaja i Tjumenochka $v$ zavisimosti ot srokov seva i norm vysevav severnoj lesostepi Tjumenskoj oblasti // Vestnik KrasGAU. 2019. № 5 (146). S. 50-62.

12. Miller S.S., Rzaeva V.V. Urozhajnost' jarovoj pshenicy po sposobam obrabotki pochvy $v$ zernopropashnom sevooborote severnoj lesostepi Tjumenskoj oblasti // AgroJekolnfo. 2018. № 4 (34). S. 13.

13. Rzaeva V.V. Vlijanie agrotehnicheskih prijomov na produktivnost' kul'tur sevooborota // Izvestija Orenburgskogo gosudarstvennogo agrarnogo universiteta. 2019. № 4 (78). S. 18-20.

14. Semenova E.A., Afanas'ev R.A. Agrojekonomicheskaja jeffektivnost' primenenija mineral'nyh udobrenij pod jarovuju pshenicu $v$ uslovijah Zaural'ja // Plodorodie. 2019. № 2 (107). S. 11-13.
15. Sychev V.G., Afanas'ev R.A. Robototehnika v tehnologijah tochnogo zemledelija // Plodorodie. 2016. № 3 (90). S. 2-6.

16. Tobolova G.V., Letjago Ju.A., Belkina R.I. Ocenka sortov mjagkoj jarovoj pshenicy po tehnologicheskim svojstvam i biohimicheskim priznakam // Agroprodovol'stvennaja politika Rossii. 2015. №5 (41). S. 64-67.

17. Chikishev D.V., Abramov N.V., Larina N.S. Vlijanie azotnyh udobrenij na aminokislotnyj sostav zerna jarovoj pshenicy // Vestnik Bashkirskogo gos. agrar. un-ta. 2019. № 3 (51). S. 20-25.

18. Sherstobitov S.V. Differencirovannoe vnesenie azotnyh udobrenij $\mathrm{s}$ ispol'zovaniem sistem sputnikovoj navigacii: avtoref. dis. ... kand. s.-h. nauk / Vseros. nauch.-issled. in-t agrohimii im. D.N. Prjanishnikova. M., 2015. $22 \mathrm{~s}$.

19. Jakushev V.V. Tochnoe zemledelie: teorija i praktika. SPb., 2016. $364 \mathrm{~s}$. 